\title{
Socioeconomic inequalities in hidden hunger, undernutrition, and overweight among under-five children in 35 sub- Saharan Africa countries
}

\author{
Michael Ekholuenetale ${ }^{1 *}$, Godson Tudeme ${ }^{2}$, Adeyinka Onikan ${ }^{3}$ and Charity E. Ekholuenetale ${ }^{4}$
}

\begin{abstract}
Background: Many underlying factors are assumed to contribute to the disparities in magnitude of childhood malnutrition. Notwithstanding, socioeconomic inequalities remain key measures to determine chronic and hidden hunger among under-five children. This study was undertaken to explore childhood malnutrition problems that are associated to household wealth-related and mother's educational attainment in sub-Saharan Africa (SSA).

Methods: Secondary data from birth histories in 35 SSA countries was used. The Demographic and Health Survey (DHS) data of 384,747 births between 2008 and 2017 in 35 countries was analyzed. The outcome variables of interest were mainly indicators of malnutrition: stunting, underweight, wasting, overweight, anemia, and under-five children survival. Household wealth-related and mother's educational level were the measures of socioeconomic status. Concentration index and Lorenz curves were the main tools used to determine inequalities for nutritional outcomes. The statistical significance level was determined at 5\%.

Results: Based on the results, Burundi (54.6\%) and Madagascar (48.4\%) accounted for the highest prevalence of stunted children. Underweight children were 32.5\% in Chad and 35.5\% in Niger. Nigeria (16.6\%) and Benin (16.4\%) had the highest burdens of wasted children. Overall, overweight and under-five survival were significantly more in the higher household wealth, compared with the lower household wealth (Conc. Index $=0.0060 ; p<0.001$ and Conc. Index $=0.0041 ; p=0.002$ respectively). Conversely, stunting (Conc. Index $=-0.1032 ; p<0.001$ ), underweight (Conc. Index $=-0.1369 ; p<0.001$ ), wasting (Conc. Index $=-0.0711 ; p<0.001$ ), and anemia (Conc. Index $=-0.0402 ; p<$ 0.001) were significantly lower in the higher household wealth status, compared with the lower household wealth groups. Furthermore, under-five children survival was significantly more from mothers with higher educational attainment, compared with children from mothers with lower educational attainment (Conc. Index $=0.0064 ; p<$ 0.001). Conversely, stunting (Conc. Index $=-0.0990 ; p<0.001$ ), underweight (Conc. Index $=-0.1855 ; p<0.001$ ), wasting (Conc. Index $=-0.1657 ; p<0.001$ ), overweight (Conc. Index $=-0.0046 ; p<0.001$ ), and anemia (Conc. Index $=$ 0.0560; $p<0.001$ ) were significantly more among children from mothers with lower educational attainment. The test for differences between children from urban vs. rural was significant in stunted, underweight, overweight, and anemia for household wealth status. Also, the difference in prevalence between children from urban vs. rural was significant in stunted, underweight, and wasted for mother's educational attainment.

(Continued on next page)
\end{abstract}

\footnotetext{
* Correspondence: mic42006@gmail.com

'Department of Epidemiology and Medical Statistics, Faculty of Public Health,

College of Medicine, University of Ibadan, Ibadan, Nigeria

Full list of author information is available at the end of the article
} 
(Continued from previous page)

Conclusion and recommendations: Reduction in malnutrition could be achieved by socioeconomic improvement that is sustained and shared in equity and equality among the populace. Interventions which target improvement in food availability can also help to achieve reduction in hunger including communities where poverty is prevalent.

Keywords: Anemia, Mortality, Overweight, Stunting, Underweight, Wasting

\section{Introduction}

Childhood malnutrition is classified as undernutrition in stunting, wasting, and underweight. On the other hand, overweight is largely noted for inappropriate feeding patterns. Much of the world's burden of malnutrition is notable in several resource-constrained settings. Children who suffer from malnutrition can be identified without special equipment or training due to associated morphological characteristics. Albeit, there are other forms of malnutrition that are less noticeable to the naked eye [1]. The World Health Organization (WHO) has estimated approximately two billion people suffer from "hidden hunger" globally [2]. This form of malnutrition tends to be hidden both to the person suffering the deficiency and to the outside world until it becomes so severe that clinical signs emerge. Promoting early childhood feeding best practices is crucial to improve the health of children [3]. A decline in malnutrition is important to achieve the Sustainable Development Goals (SDGs), especially those targeted to end poverty in all its forms everywhere (SDG 1), end hunger, achieve food security, improve nutrition, promote sustainable agriculture (SDG 2), ensure healthy lives, and promote well-being for all at all ages (SDG 3) $[4,5]$. Due to the effects of childhood undernutrition, governments have made commitments to the global targets to reduce chronic undernutrition (stunting) by $40 \%$ by 2025 and also to reduce and maintain the prevalence of acute undernutrition (wasting) to less than $5 \%$ in children under 5 years of age [6].

Globally, hidden hunger afflicts a large number of people [7] and has numerous adverse effects including, poor health, retarded growth, low productivity, mental impairment, and unexpected death. Its effects on children's health or survival can be acute, specifically from conception and up to 2 years of age or within the first 1000 days of life, leading to severe cognitive and physical consequences [8]. Worst still, lack of micronutrient can affect a child adversely. Besides, hidden hunger can hamper socioeconomic development within communities, especially in resource-constrained settings. Food and Agriculture Organization (FAO) reported that about 842 million people worldwide were unable to obtain their dietary energy needs between 2011 and 2013, compared with about 868 million people estimated between 2010 and 2012. By implication, one in eight persons worldwide has the likelihood to suffer from chronic hunger, which means lack of sufficient food for a healthy life. The staggering number of hungry people, about 827 million, dwell in poor-resource settings, where the prevalence of undernutrition is now estimated at $14.3 \%$ [7].

In spite of the efforts to reduce malnutrition, disparities across regions persist. The sub-Saharan Africa region has the highest prevalence of undernutrition, with sparse progress in recent time [7]. Hidden hunger as a type of undernutrition happens when the intake of micronutrients including vitamins and minerals are inadequate for optimal growth [9]. Poor diet remains the major factor that contributes to micronutrient deficiencies. The magnitude of malnutrition in the world today is worrisome. Nowadays, resource-constrained settings are changing from traditional diets made from less processed foods to greater energy-dense, processed, micronutrient-poor foods, which cause large increase in body weight and other noncommunicable diseases. In the advent of these changes in nutrition, several countries now face the "triple burden" which includes lack of micronutrient, undernourishment, and overweight [10]. In more urbanized, higher income countries, hidden hunger co-exist with overweight or obesity when people feed more on macronutrients such as fats and carbohydrates [11]. Though it seems counterintuitive, an overweight child can actually suffer from hidden hunger.

Chronic or hidden hunger causes about one third of childhood deaths that occur annually [12, 13]. Interventions to end hidden hunger and improve nutritional outcomes commonly target children. Considering this population, programs and interventions achieve success by improving health, nutritional status, and cognition later in life [14]. Though children are reported as the key population affected by hidden hunger, however, it impedes the health of all people. There are two mechanisms involved in accessing food which include physical and economic accessibility. The economic access could be decided by food prices, income, and access to social support. More so, the physical access could be decided by the quality and availability of infrastructure, such as roads, ports, communication, and food storage facilities, and other resources that enhance the functioning of markets [7].

There is evidence that efforts to enhance the health and well-being of children have paid-off by a reduction in childhood death by about half between 1990 and 2013 
[15]. Similarly, efforts to improve childhood survival in SSA region led to a decline from 180 deaths per 1000 live births in 1990 to 83 deaths per 1000 live births in 2015 [13]. Addressing the risk factors for poor childhood health as identified in evidence-based studies [16-18] may have led to the past gains. The prominent factors identified to be responsible for poor growth and development include sub-optimal childhood feeding practices and infections $[19,20]$. Several childhood feeding practices including inadequate breastfeeding or non-exclusive breastfeeding and complementary feeding that are insufficient in quality and quantity contribute to childhood malnourishment [19]. Also, infections, household poverty, caregiver neglect, or ignorance and food insecurity could have agelong adverse effect on children's growth [19]. In light of the above, we have identified a number of studies on potential predictors of nutrition outcomes that have increased steeply over the last decades. Social support, availability and accessibility of food, and socioeconomic status are significant for nutritional behaviors [21]. In this paper, we endeavor to quantify inequalities in childhood malnutrition that are ascribable to individual and household socioeconomic status.

\section{Methods}

\subsection{Data source}

Here, we used secondary multi-country DHS data from birth histories in 35 SSA countries. Data of children born in the 5 years prior to the surveys were used and a large pooled sample of 384,747 births between 2008 and 2017 in various countries. The data is available in the public domain and accessed at http://dhsprogram.com/ data/available-datasets.cfm. DHSs were based on a stratified multi-stage cluster sampling technique. The stratification strategy divides the population into groups. For instance, all DHS employ a region crossed by urbanrural stratification. The consideration of demographic differences in urban and rural areas supports the relatively independent designs in urban and rural areas and therefore the region crossed by urban-rural stratification. A multi-level stratification approach is used to divide the population into first-level strata and to subdivide the first-level strata into second-level strata, and so on. The two-level stratification in DHS is region and urban/rural stratification. DHS data are collected on vital sexual and reproductive health issues through interviewer's administered questionnaires. A crucial component of the data collection is the maternity history; where women were asked about their birth histories. Thirty-five countries in SSA region were included based on availability of current data.

DHS are comparable household surveys that have been conducted in more than 85 countries worldwide since 1984. Though initially designed to expand on demographic, fertility and family planning data collected in the World Fertility Surveys and Contraceptive Prevalence Surveys, DHS continue to provide an important resource for the monitoring of vital statistics and population health indicators in resource-constrained settings. It collects a wide range of objective and self-reported data with a strong focus on indicators of fertility, reproductive health, maternal and child health, mortality, nutrition, and self-reported health behaviors among adults. Key advantages of the DHS include national coverage, high-quality interviewer training, standardized data collection procedures across countries and consistent content over time, allowing comparability across populations cross-sectionally and over time. Data from DHS facilitate epidemiological research focused on monitoring of prevalence, trends, and inequalities. A variety of robust observational data analysis methods have been used, including cross-sectional designs, repeated crosssectional designs, spatial and multi-level analyses, intrahousehold designs and cross-comparative analyses [22].

\subsection{Variables selection and measurement 2.2.1 Outcome variable}

2.2.1.1 Anemia The hemoglobin levels were measured using the blood of the children collected through a finger or heel prick. Anemia was classified into; mild, moderate, severe or not anemic. The cut-off values of anemia were $10.0-10.9 \mathrm{~g} / \mathrm{dl}$ (mild), $9.0-9.9 \mathrm{~g} / \mathrm{dl}$ (moderate), < $9.0 \mathrm{~g} / \mathrm{dl}$ (severe) and $\geq 11 \mathrm{~g} / \mathrm{dl}$ (not anemic). Dichotomously, this was grouped as $<11 \mathrm{~g} / \mathrm{dl}$ (anemic) vs. $\geq 11 \mathrm{~g} /$ $\mathrm{dl}$ (not anemic)

2.2.1.2 Childhood survival The survival status of a child aged 0 to 59 months was measured to determine whether a child was alive vs. dead at the time of the survey.

2.2.1.3 Anthropometric measurement This was calculated using the new Child Growth Standards released by the World Health Organization on 27 April 2006. Zscores for weight-for-height (WHZ), height-for-age (HAZ), and weight-for-age (WAZ) were calculated using the WHO growth standards [23]. The following standard case-definitions were applied to each record:

- Acute malnutrition/wasting. This was calculated using weight-for-height. Children that were below 2 SD from the reference median were classified wasted.

- Underweight. This was calculated based on weightfor-age, that is, a child is too thin for his/her age. Children whose weight-for-age is below - 2 SD from the reference population median were classified as underweight. 
- Overweight. This was calculated by the weight-forheight. Children that are above +2 SD from the reference median are considered overweight.

- Stunting. This was calculated based on height-forage. Z-score (HAZ) below - 2 SD from the median of the WHO reference population was considered stunted or chronically malnourished.

\subsubsection{Explanatory variables}

2.2.2.1 Place of residence This was classified as urban vs. rural.

2.2.2.2 Mother's educational level This was measured as no formal education, primary, secondary, or higher.

2.2.2.3 Wealth index Wealth quintiles variable was computed by DHS using principal components analysis (PCA) to assign the wealth indicator weights. In their computation, they assigned scores and standardized the wealth indicator variable using household assets such as floor type, wall type, roof type, water source, sanitation facilities, radio, electricity, television, refrigerator, cooking fuel, furniture, and number of persons per room. Then, the factor loadings and $z$-scores were calculated. For each household, they multiplied the indicator values by the loadings and summed to produce the household's wealth index value. The standardized $z$-score was finally used to classify the overall scores to wealth quintiles: poorest, poorer, middle, richer, and richest [24]. Household wealth quintiles and mothers' educational attainment were used as measures of socioeconomic status similar to previous studies [25-27].

\subsection{Data analysis plan}

Stata module survey ("svy") command was used to adjust for stratification, clustering, and sampling weights in data analysis. Percentage and Chi-square test were used for summary statistics and bivariate analysis. Lorenz curves and concentration index were used to examine socioeconomic inequalities for nutritional outcomes. Concentration Index is positive when the Lorenz curve is below the line of equality indicating that the burden of chronic and hidden hunger is greater among high socioeconomic groups. Similarly, when concentration index value is negative, it shows that the burden of chronic and hidden hunger is higher among low socioeconomic groups. The urban vs. rural place of residence was used for stratified analyses. Lorenz curves and concentration index were used to compute contrast between various outcome variables [28]. Statistical significance was determined at $p<$ 0.05. Data analysis was conducted using Stata Version 14 (StataCorp., College Station, TX, USA).

\subsection{Ethical consideration}

This study was based on an analysis of population-based datasets that exist in the public domain and available online. The authors communicated with MEASURE DHS/ ICF International and permission was granted to download and use the data. The DHS project obtained the required ethical approvals from the relevant research ethics committee in each country before the surveys were conducted. Measure DHS/ICF International approved the usage of the data for this study.

\section{Results}

Table 1 shows that under-five mortality was lowest in Gambia (3.7\%) and South Africa (3.8\%) but highest in Chad (9.3\%) and Sierra Leone (11.1\%). Burundi (54.6\%) and Madagascar (48.4\%) accounted for the highest prevalence of stunted children. Furthermore, underweight children were 32.5\% in Chad and 35.5\% in Niger which had the highest burdens of underweight children in sub-Saharan Africa countries. Nigeria (16.6\%) and Benin (16.4\%) had the highest burdens of wasted children. Overweight children were majorly reported from Namibia (70.3\%), Malawi (71.3\%), Uganda (72.7\%), and South Africa (73.5\%). It was worrisome to find that majorities of children in sub-Saharan Africa countries had anemia (mild, moderate, and severe).

Table 2 presents the percentages of stunting, underweight, wasting, overweight, anemia, and children under- 5 years who survived to the date of the surveys across household wealth quintile and mother's education. Based on the results, rural children were more stunted, underweight, wasted, and anemic across household wealth quintile and levels of mother's education, compared with the urban children. However, urban children were more overweight and had higher under-five survival across household wealth quintile and mother levels of mother's education, compared with their rural counterpart. Furthermore, the concentration index, quantified the degree of wealth-related and mother's education inequalities in stunting, underweight, wasting, overweight, anemia, and under-five survival. Overall, overweight and under-five survival were significantly more in higher household wealth, compared to the lower household wealth groups, (Conc. Index $=0.0060 ; p<$ 0.001 ) and under-five survival (Conc. Index $=0.0041 ; p$ $=0.002$ ), respectively. Conversely, stunting (Conc. Index $=-0.1032 ; p<0.001)$, underweight (Conc. Index $=-$ $0.1369 ; p<0.001$ ), wasting (Conc. Index $=-0.0711 ; p<$ 0.001 ), and anemia (Conc. Index $=-0.0402 ; p<0.001$ ) were significantly lower in the higher household wealth status, compared to the lower household wealth groups. Furthermore, under-five children survival was significantly more from mothers with higher educational attainment, compared with children from mothers with lower educational attainment (Conc. Index $=0.0064 ; p<$ 
Table 1 Summary statistics from 35 SSA countries on nutrition indicators among under-five children; DHS, 2008-2017

\begin{tabular}{|c|c|c|c|c|c|c|c|c|c|c|}
\hline \multirow[t]{2}{*}{ Country } & \multirow{2}{*}{$\begin{array}{l}\text { Study } \\
\text { year }\end{array}$} & \multirow{2}{*}{$\begin{array}{l}\text { Sample } \\
\text { size }(n)\end{array}$} & \multirow{2}{*}{$\begin{array}{l}\text { Stunted } \\
(\%)\end{array}$} & \multirow{2}{*}{$\begin{array}{l}\text { Under-5 death } \\
\text { (\%) }\end{array}$} & \multirow{2}{*}{$\begin{array}{l}\text { Underweight } \\
\text { (\%) }\end{array}$} & \multirow{2}{*}{$\begin{array}{l}\text { Wasted } \\
(\%)\end{array}$} & \multirow{2}{*}{$\begin{array}{l}\text { Overweight } \\
\text { (\%) }\end{array}$} & \multicolumn{3}{|l|}{ Anemia } \\
\hline & & & & & & & & $\begin{array}{l}\text { Mild } \\
(\%)\end{array}$ & $\begin{array}{l}\text { Moderate } \\
(\%)\end{array}$ & $\begin{array}{l}\text { Severe } \\
(\%)\end{array}$ \\
\hline \multicolumn{11}{|l|}{ Central SSA } \\
\hline Madagascar & 2008/09 & 12,448 & 48.4 & 5.6 & & & & 30.4 & 19.6 & 0.9 \\
\hline Angola & 2015/16 & 14,322 & 37.4 & 4.9 & 19.4 & 5.1 & 56.8 & 30.1 & 32.1 & 2.6 \\
\hline Congo & $2011 / 12$ & 9329 & 26.8 & 5.1 & 13.0 & 5.5 & 53.7 & 31.5 & 33.5 & 1.2 \\
\hline Gabon & 2012 & 6067 & 22.9 & 5.3 & 8.3 & 4.1 & 48.3 & 29.5 & 32.5 & 1.8 \\
\hline $\begin{array}{l}\text { Democratic Republic } \\
\text { of Congo }\end{array}$ & 2013/14 & 18,716 & 44.1 & 8.0 & 23.2 & 7.9 & 58.7 & 24.7 & 34.6 & 3.7 \\
\hline Total estimate & 2008-2016 & 60,882 & 37.8 & 6.1 & 17.8 & 6.0 & 54.6 & 28.7 & 30.7 & 2.3 \\
\hline$P$ & & & $<0.001$ & $<0.001$ & $<0.001$ & $<0.001$ & $<0.001$ & $<0.001$ & $<0.001$ & $<0.001$ \\
\hline \multicolumn{11}{|l|}{ East SSA } \\
\hline Burundi & 2016/17 & 13,192 & 54.6 & 5.5 & 28.9 & 5.1 & 54.8 & 24.9 & 30.9 & 3.3 \\
\hline Comoros & 2012 & 3149 & 27.7 & 4.0 & 14.5 & 11.7 & 30.8 & & & \\
\hline Ethiopia & 2016 & 10,641 & 36.4 & 6.0 & 25.3 & 12.1 & 18.0 & 23.7 & 32.5 & 4.0 \\
\hline Kenya & 2014 & 20,964 & 27.1 & 4.2 & 13.2 & 5.5 & 14.2 & & & \\
\hline Malawi & 2015/16 & 17,286 & 35.2 & 4.8 & 12.0 & 3.2 & 71.3 & 27.0 & 34.4 & 1.8 \\
\hline Mozambique & 2011 & 11,102 & 39.3 & 7.3 & 13.1 & 5.2 & 22.6 & 26.2 & 36.7 & 3.4 \\
\hline Rwanda & $2014 / 15$ & 7856 & 37.4 & 3.8 & 9.0 & 2.2 & 58.6 & 20.4 & 14.7 & 0.7 \\
\hline Tanzania & 2015/16 & 10,233 & 33.6 & 5.1 & 13.7 & 4.9 & 15.6 & 27.2 & 29.7 & 1.5 \\
\hline Uganda & 2016 & 15,522 & 28.4 & 5.2 & 10.8 & 3.9 & 72.7 & 24.4 & 27.8 & 2.3 \\
\hline Zambia & 2013/14 & 13,457 & 39.6 & 5.5 & 14.9 & 6.3 & 20.1 & & & \\
\hline Total estimate & 2011-2016 & 123,402 & 35.3 & 5.2 & 15.7 & 6.0 & 39.0 & 25.1 & 30.3 & 2.6 \\
\hline P & & & $<0.001$ & $<0.001$ & $<0.001$ & $<0.001$ & $<0.001$ & $<0.001$ & $<0.001$ & $<0.001$ \\
\hline \multicolumn{11}{|l|}{ South SSA } \\
\hline Lesotho & 2014 & 3138 & 34.6 & 7.1 & 11.2 & 3.5 & 61.6 & 25.5 & 26.3 & 1.7 \\
\hline South Africa & 2016 & 3548 & 25.9 & 3.8 & 5.7 & 2.9 & 73.5 & 25.8 & 32.6 & 2.7 \\
\hline Namibia & 2013 & 5046 & 23.2 & 4.5 & 13.8 & 8.0 & 70.3 & 24.7 & 25.4 & 1.0 \\
\hline Zimbabwe & 2015 & 6132 & 25.6 & 5.3 & 7.7 & 3.5 & 24.8 & 22.2 & 15.4 & 0.5 \\
\hline Total estimate & 2013-2016 & 17,864 & 26.5 & 5.1 & 9.0 & 4.2 & 53.8 & 23.6 & 20.9 & 1.0 \\
\hline P & & & $<0.001$ & $<0.001$ & $<0.001$ & $<0.001$ & $<0.001$ & $<0.001$ & $<0.001$ & $<0.001$ \\
\hline \multicolumn{11}{|l|}{ West SSA } \\
\hline Sao Tome and Principe & 2008/09 & 1931 & 27.6 & 4.1 & 13.3 & 12.3 & 32.9 & 31.5 & 27.9 & 1.0 \\
\hline Nigeria & 2013 & 31,482 & 36.1 & 9.2 & 26.9 & 16.6 & 25.2 & & & \\
\hline Guinea & 2012 & 7039 & 30.8 & 8.7 & 17.8 & 9.9 & 57.7 & 23.4 & 45.2 & 7.6 \\
\hline Niger & 2012 & 12,558 & 41.9 & 7.6 & 35.5 & 18.3 & 63.0 & 26.1 & 46.0 & 2.8 \\
\hline Benin & 2012 & 13,407 & 44.0 & 5.4 & 21.5 & 16.4 & 53.0 & 26.4 & 29.4 & 2.9 \\
\hline Cameroon & 2011 & 11,732 & 31.6 & 8.5 & 13.7 & 5.4 & 59.8 & 27.8 & 32.3 & 2.0 \\
\hline Chad & $2014 / 15$ & 18,623 & 42.9 & 9.3 & 32.5 & 14.2 & 48.5 & & & \\
\hline Ghana & 2014 & 5884 & 19.2 & 4.9 & 11.0 & 4.9 & 54.9 & 27.4 & 39.4 & 2.8 \\
\hline Burkina-Faso & 2010 & 15,044 & 34.2 & 8.8 & 24.9 & 15.3 & 57.6 & 18.5 & 59.0 & 10.9 \\
\hline Cote d'Ivoire & $2011 / 12$ & 7776 & 29.8 & 8.8 & 14.6 & 7.1 & 60.0 & 24.9 & 47.0 & 3.5 \\
\hline Liberia & 2013 & 7606 & 30.9 & 7.2 & 15.3 & 6.6 & 59.5 & & & \\
\hline Mali & 2012/13 & 10,326 & 37.8 & 7.2 & 25.2 & 12.6 & 59.1 & 21.4 & 51.1 & 8.6 \\
\hline Senegal & 2017 & 12,185 & 19.1 & 4.8 & 16.4 & 9.6 & 12.3 & 27.9 & 43.0 & 3.4 \\
\hline
\end{tabular}


Table 1 Summary statistics from 35 SSA countries on nutrition indicators among under-five children; DHS, $2008-2017$ (Continued)

\begin{tabular}{|c|c|c|c|c|c|c|c|c|c|c|}
\hline \multirow[t]{2}{*}{ Country } & \multirow{2}{*}{$\begin{array}{l}\text { Study } \\
\text { year }\end{array}$} & \multirow{2}{*}{$\begin{array}{l}\text { Sample } \\
\text { size }(n)\end{array}$} & \multirow{2}{*}{$\begin{array}{l}\text { Stunted } \\
(\%)\end{array}$} & \multirow{2}{*}{$\begin{array}{l}\text { Under-5 death } \\
\text { (\%) }\end{array}$} & \multirow{2}{*}{$\begin{array}{l}\text { Underweight } \\
\text { (\%) }\end{array}$} & \multirow{2}{*}{$\begin{array}{l}\text { Wasted } \\
(\%)\end{array}$} & \multirow{2}{*}{$\begin{array}{l}\text { Overweight } \\
\text { (\%) }\end{array}$} & \multicolumn{3}{|l|}{ Anemia } \\
\hline & & & & & & & & $\begin{array}{l}\text { Mild } \\
(\%)\end{array}$ & $\begin{array}{l}\text { Moderate } \\
(\%)\end{array}$ & $\begin{array}{l}\text { Severe } \\
(\%)\end{array}$ \\
\hline Sierra Leone & 2013 & 11,938 & 37.7 & 11.1 & 16.0 & 9.4 & 68.8 & 26.2 & 47.6 & 6.6 \\
\hline Togo & $2013 / 14$ & 6979 & 28.3 & 6.4 & 16.8 & 7.3 & 55.2 & 26.0 & 42.4 & 2.6 \\
\hline Gambia & 2013 & 8088 & 25.8 & 3.7 & 18.0 & 11.7 & 62.8 & 24.4 & 44.8 & 4.7 \\
\hline Total estimate & 2010-2015 & 182,598 & 33.9 & 7.8 & 22.6 & 12.8 & 49.0 & 25.3 & 44.1 & 4.9 \\
\hline$P$ & & & $<0.001$ & $<0.001$ & $<0.001$ & $<0.001$ & $<0.001$ & $<0.001$ & $<0.001$ & $<0.001$ \\
\hline
\end{tabular}

$P$ value was obtained using Chi-square

0.001). More so, stunting (Conc. Index $=-0.0990 ; p<$ 0.001 ), underweight (Conc. Index $=-0.1855 ; p<0.001$ ), wasting (Conc. Index $=-0.1657 ; p<0.001$ ), overweight (Conc. Index $=-0.0046 ; p<0.001$ ), and anemia (Conc. Index $=0.0560 ; p<0.001)$ were significantly more among children from mothers with lower educational attainment. The test for differences between children from urban vs. rural was significant in stunting, underweight, overweight, and anemia for household wealth status.

Figures 1, 2, 3, 4, 5, and 6 show the household wealthrelated inequalities for the stunting, wasting, underweight, overweight, anemia, and under-five children survival. The more the Lorenz curves sags away from the line of equality, the greater the degree of inequality. The inequalities in household wealth level were more among stunted, underweight, and anemic urban children, as the areas between the curve and the line of inequality was maximal. This is consistent with the results obtained from the concentration index model $(-0.0036$, -0.1304 , and -0.0486 , respectively).

Figures 7, 8, 9, 10, 11, and 12 show mothers' educational attainment inequalities for the stunting, wasting, underweight, overweight, anemia, and under-five children survival. The farther the Lorenz curves draw away from the line of equality, the higher the degree of inequality. The inequalities in mother's educational attainment varied among children by nutritional indicators, as the areas between the curve and the line of inequality was maximal. For example, comparing with the outcome of the concentration index, overall, stunting $(-0.0990)$, underweight $(-0.1855)$, wasting $(-0.1657)$, overweight $(-00046)$, and anemia $(-0.0560)$ were higher among children from lower mother's education.

\section{Discussion}

The findings in the paper suggest that sub-Saharan Africa countries have disparities on several indicators of malnutrition including stunting, underweight, wasting, overweight, anemia, and childhood survival. Interestingly, this paper contributes to this growing empirical literature on household wealth-related and maternal education inequalities in child malnutrition. In this study, we investigated that socioeconomic inequalities in malnutrition is present in sub-Saharan African children. The key findings indicated that the disadvantaged have more burdens from malnutrition, and that the resultant inequalities were higher for other malnutrition indicators except for childhood survival. There is consistency of this results with previous evidence that reported that socioeconomic status has effect on the conditions that precipitated malnourishment [29-31]. By using concentration index and Lorenz curves to examine socioeconomic inequalities in childhood malnutrition, to draw viable conclusions about regional inequalities in malnutrition makes this paper very unique.

Furthermore, inequalities in mother's education and indicators of malnutrition were a notable finding in this study. This is in line with reports from a previous study [32]. The contribution of mother's education to the inequalities in childhood malnutrition could be due to differences in the knowledge or ability of mothers to decide proper nutrition for children in terms of balanced diets and accessibility to food commodities. This factor is a key determinant associated with inequality in childhood malnutrition. Previous studies have reported the function of mother's education in malnutrition, either by investigating inequalities [33, 34] or by measuring malnutrition and its associated factors [35, 36].

\subsection{Strengths and limitations}

The major strength was the use of multi-country large data sets which provide generalizable estimates. In addition, the data allowed large reporting of the prevalence of chronic and hidden hunger among under-five children. However, using a cross-sectional study, we collected data across a number of countries at different points in time. Therefore, the distribution of nutritional outcomes could have changed over time. Also, DHS does not collect data on household income or expenditure, which are the traditional indicators used to measure wealth. The assets-based wealth index used here is only a proxy indicator for household economic status, and it does not always produce results similar to those obtained from direct measurements of income and expenditure where such data are available or can be collected reliably. 


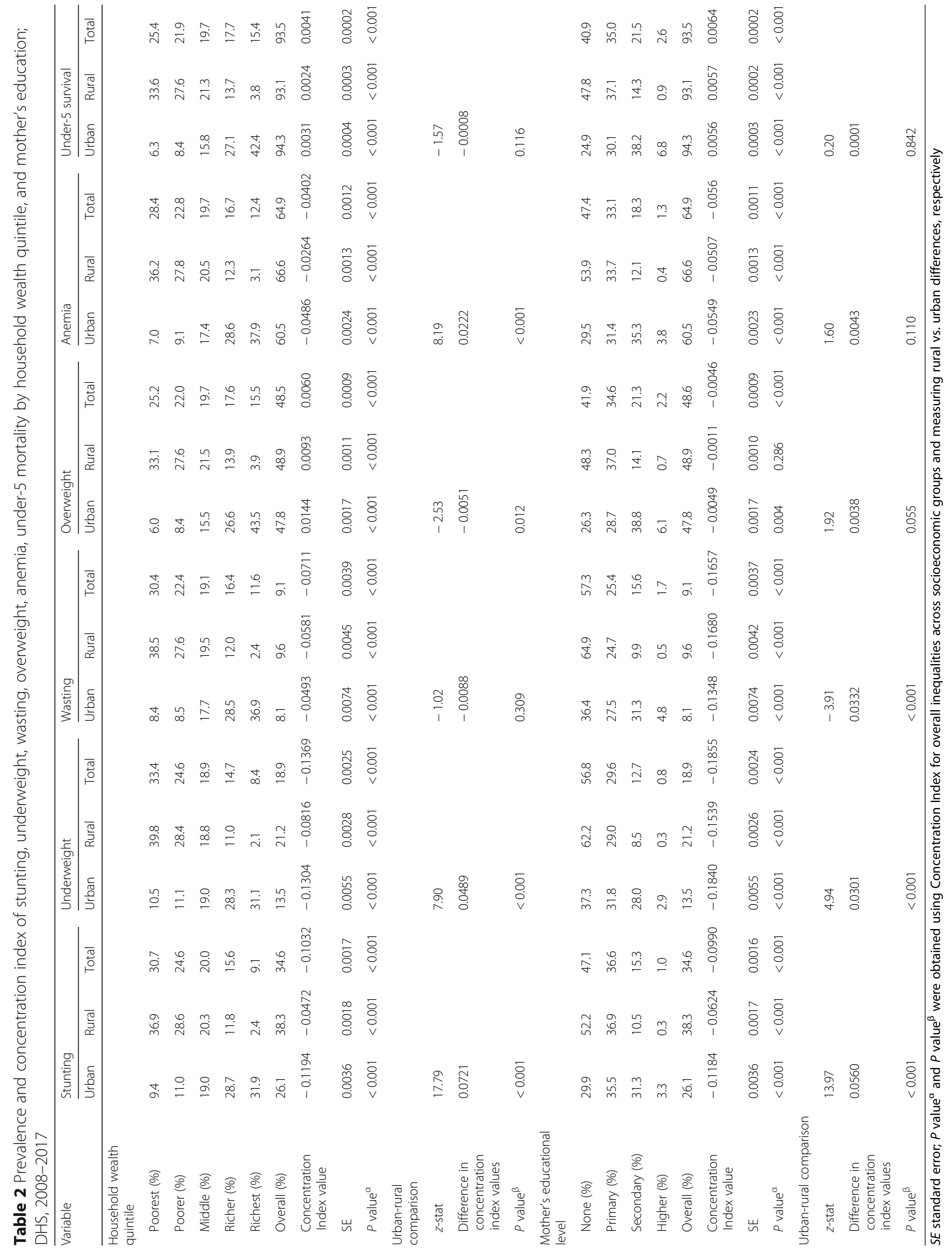




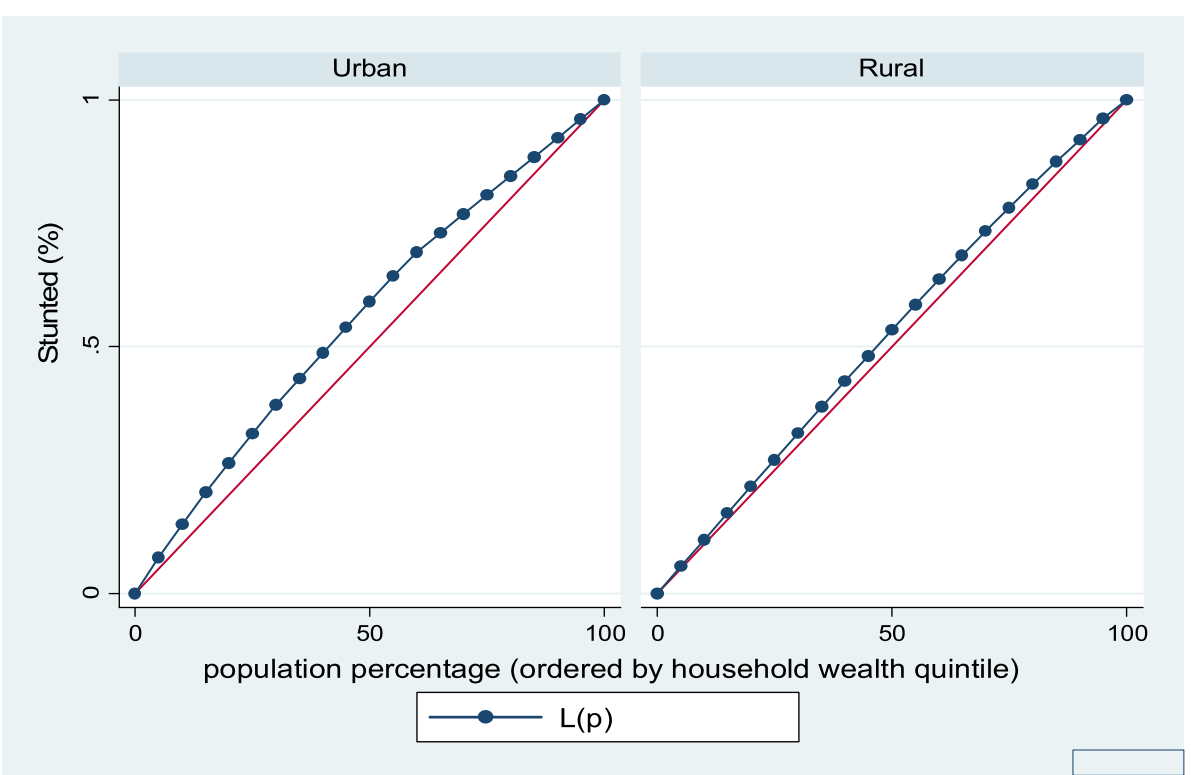

Fig. 1 Urban-rural Lorenz curve for stunting

\section{Conclusion and recommendations}

To end the problems of childhood malnutrition, improvements in maternal education and household wealth status are required, especially initiatives that go beyond the limits of the medical domain. Proper nutrition, resulting in healthy growth would help to reduce chronic and hidden hunger and their associated morbidity and mortality, particularly among the poor and the rural dwellers. In resource-constrained settings, reduction in hunger could be achieved with socioeconomic improvement that is not only sustained, but also shared in equity and equality among the populace. Interventions which target improvement in food availability and agricultural productivity can also help to achieve hunger

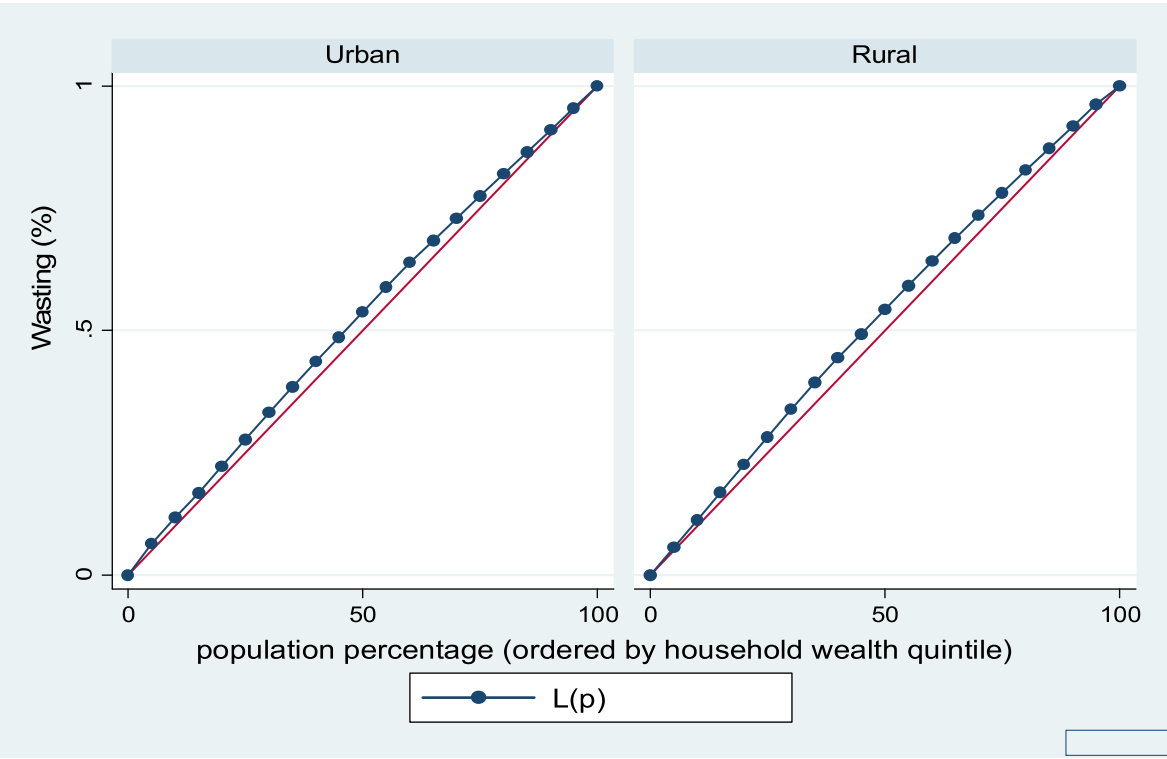

Fig. 2 Urban-rural Lorenz curve for wasting 


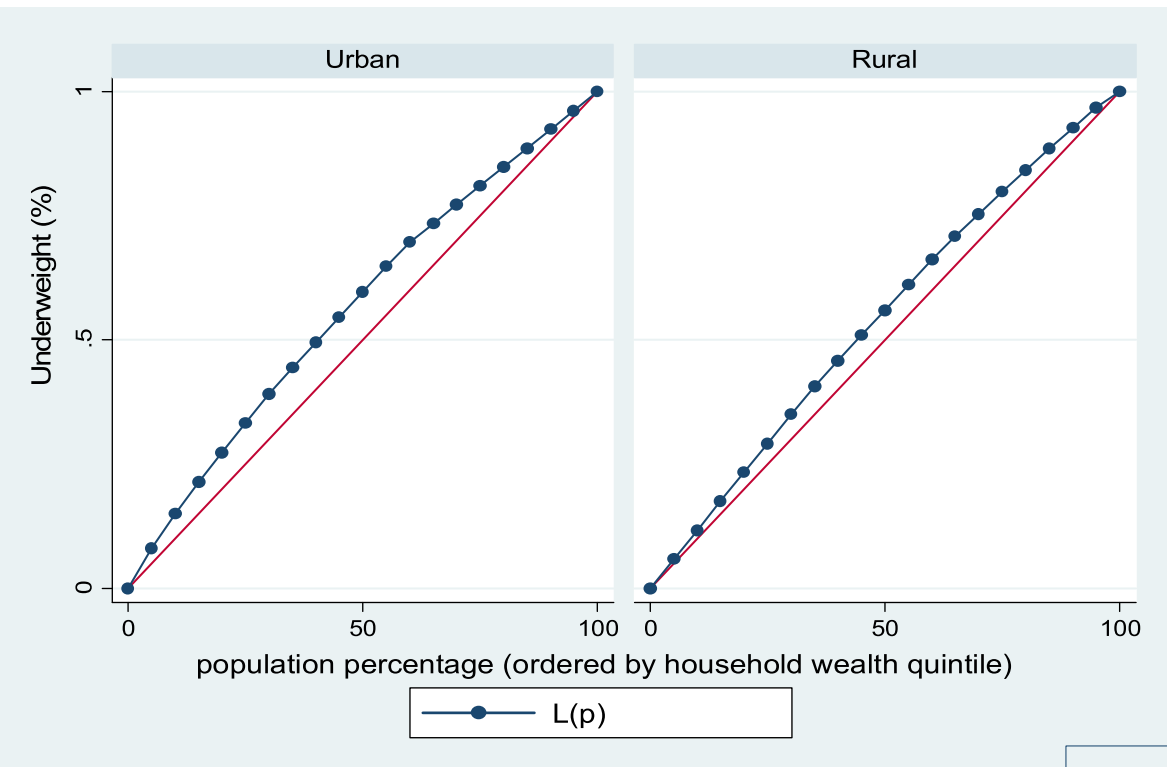

Fig. 3 Urban-rural Lorenz curve for underweight

reduction. When these combine with social protection and various measures that increase the incomes of the disadvantaged families to acquire food commodities, they can have more positive effect and instigate rural development, through creation of active markets and employment opportunities, leading to equitable economic growth at large. Ministries, agencies, and non-governmental organizations should form an alliance to improve food security and develop policies or programs to address the issue of hunger. Women's empowerment should be encouraged as a tool to address chronic and hidden hunger in sub-Saharan Africa.

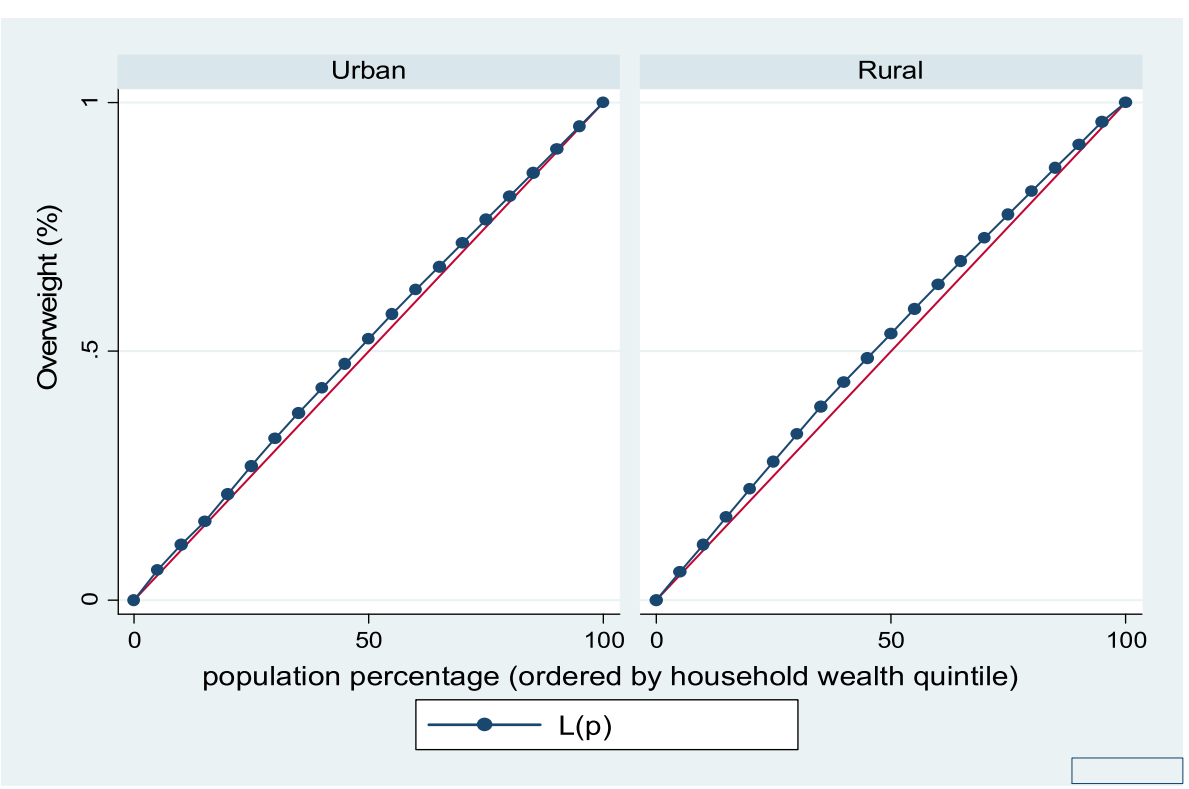

Fig. 4 Urban-rural Lorenz curve for overweight 


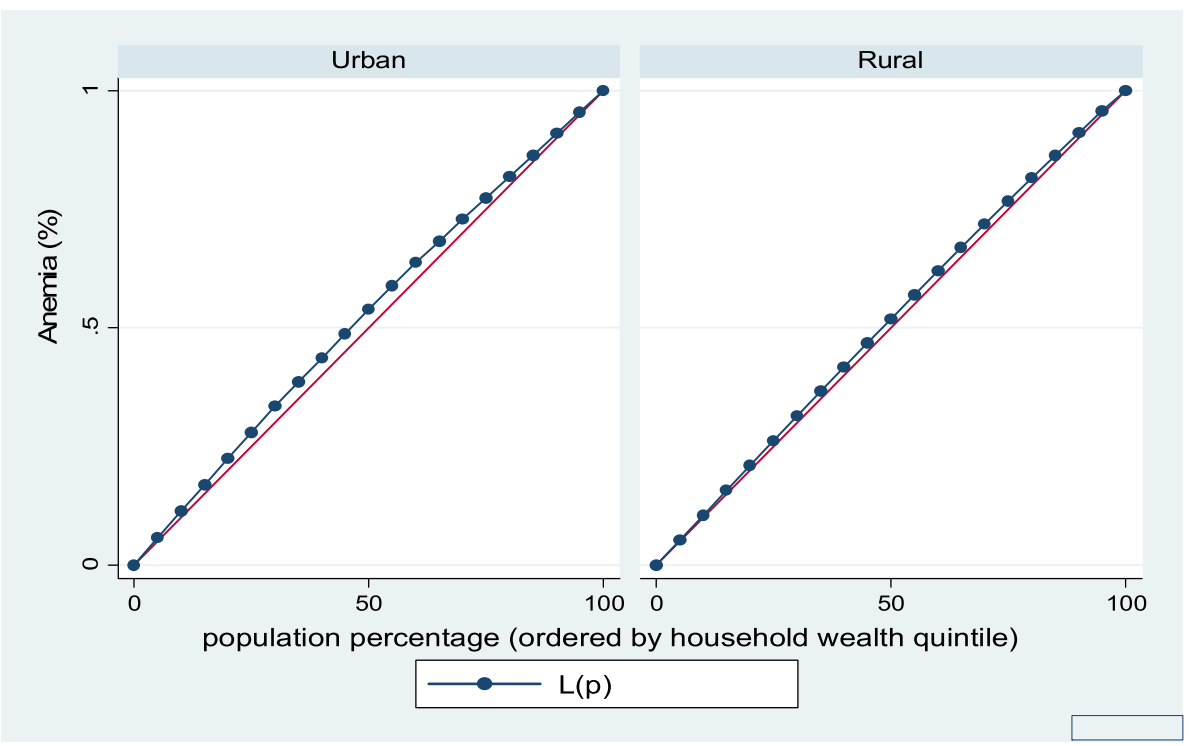

Fig. 5 Urban-rural Lorenz curve for anemia

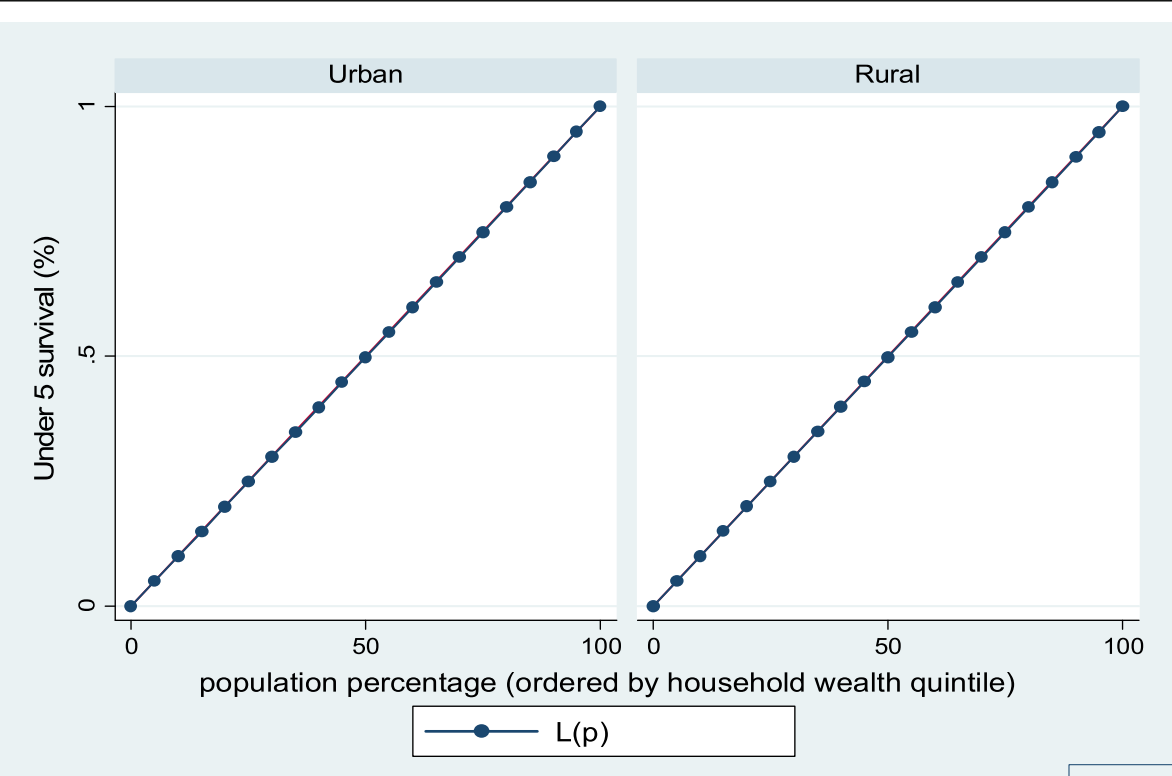

Fig. 6 Urban-rural Lorenz curve for childhood survival 


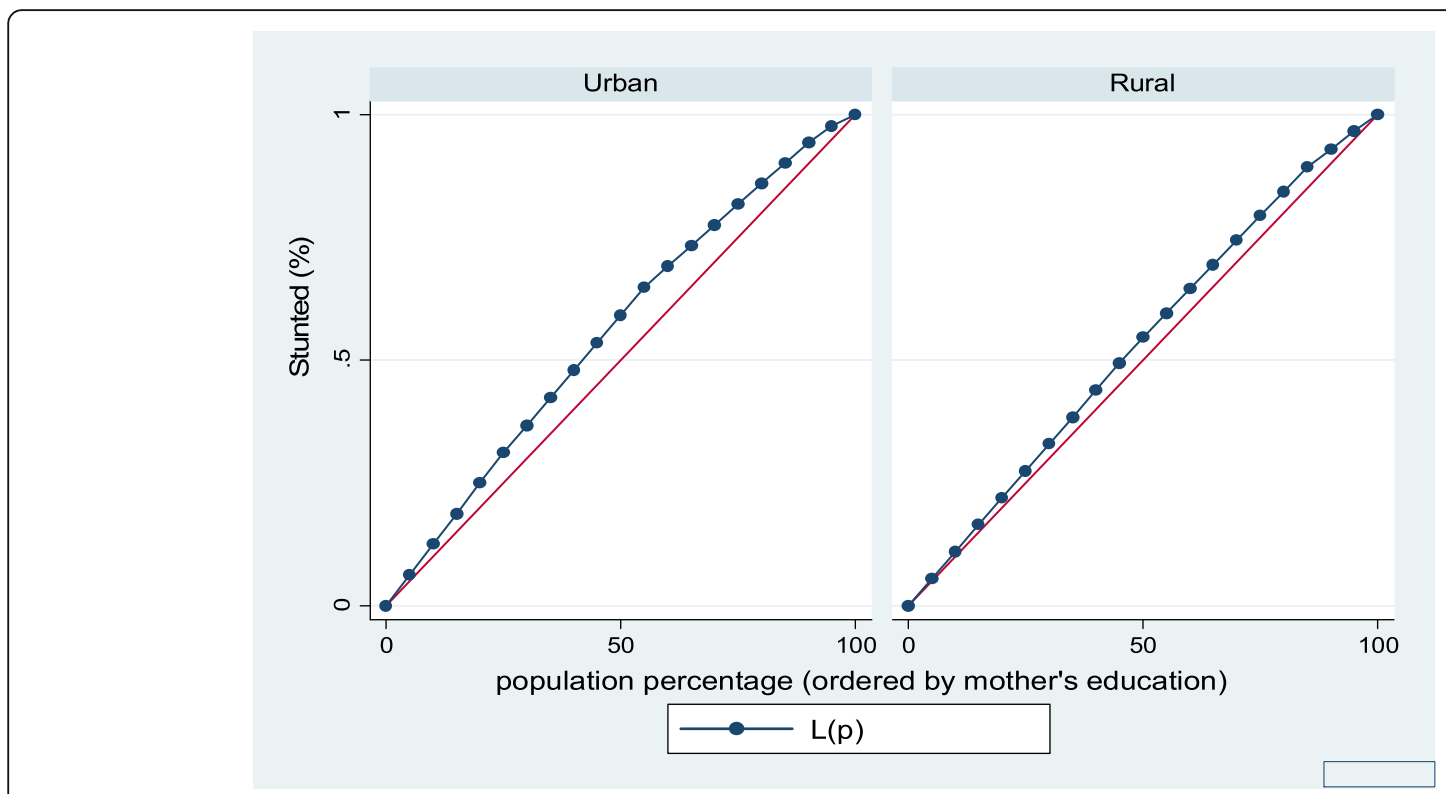

Fig. 7 Urban-rural Lorenz curve for stunting

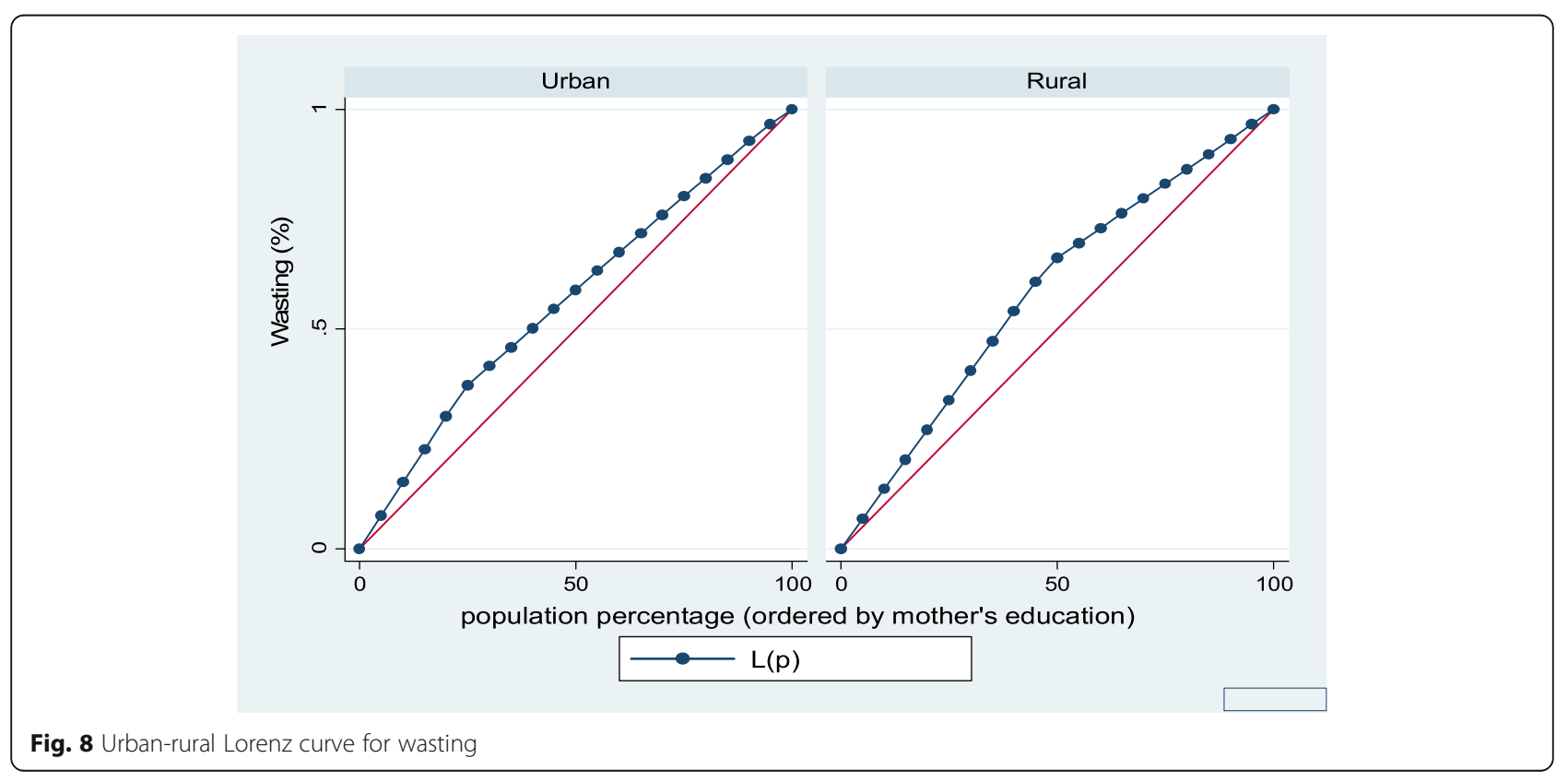



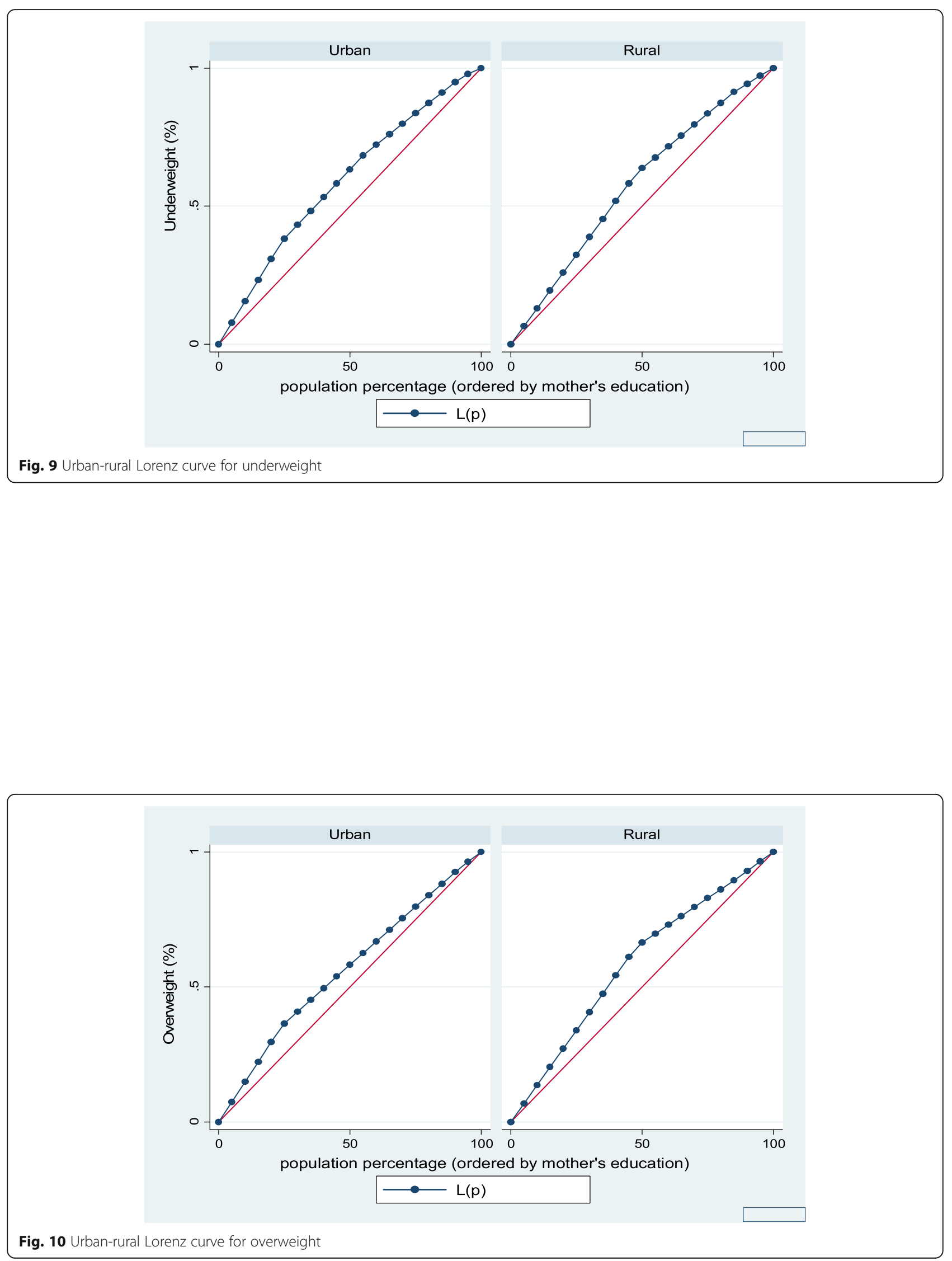

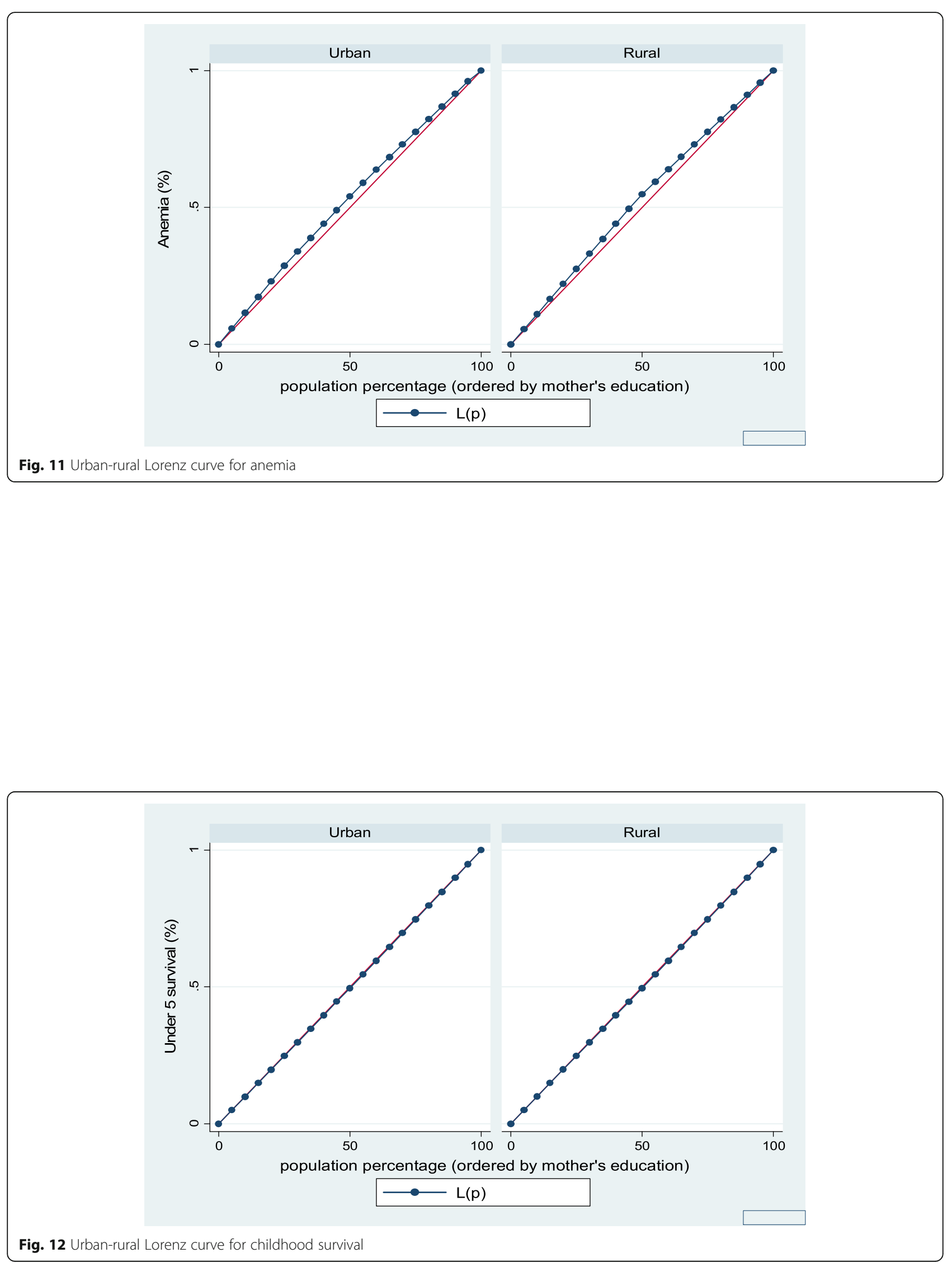


\section{Acknowledgements}

The authors appreciate the MEASURE DHS project for the approval and access to the original data.

\section{Authors' contributions}

ME conceived and designed the study, performed data analysis, and wrote the results. GT, AO, and CEE contributed to the review of literature, discussion of the findings, and critically reviewed the manuscript for its intellectual content. All authors read and approved the final version of the manuscript. ME had the responsibility to submit the manuscript.

\section{Funding}

This research received no grant from any funding agency in the public, commercial, or not-for-profit sectors.

\section{Availability of data and materials}

Data sources were from Demographic and Health surveys (DHS) and available here: http://dhsprogram.com/data/available-datasets.cfm

\section{Ethics approval and consent to participate}

Ethics approval for this study was not required since the data is secondary and is available in the public domain. More details regarding DHS data and ethical standards are available at http://dhsprogram.com/data/availabledatasets.cfm

This study does not have a participate section (secondary data analysis), so that is not applicable.

\section{Consent for publication}

Demographic and Health Survey is a de-identified open-source dataset. Therefore, the requirement of consent for publication is not applicable.

\section{Competing interests}

The authors declare that they have no competing interests.

\section{Author details}

'Department of Epidemiology and Medical Statistics, Faculty of Public Health, College of Medicine, University of Ibadan, Ibadan, Nigeria. ${ }^{2}$ School of Medicine, College of Medical Sciences, University of Benin, Benin City, Nigeria. ${ }^{3}$ Management Sciences for Health, Block B, Plot 564/565 Independence Avenue, Central Business District, FCT, Abuja, Nigeria. ${ }^{4}$ Department of Economics, Benin Study Center, National Open University of Nigeria, Abuja, Nigeria.

Received: 23 July 2019 Accepted: 30 December 2019

\section{0}

\section{References}

1. Burchi F, Fanzo J, Frison E. The role of food and nutrition system approaches in tackling hidden hunger. Int J Environ Res Public Health. 2011; 8(2):358-73.

2. World Health Organization. Global action plan for the prevention and control of noncommunicable diseases: 2013-2020. [Internet]. 2013. http:// apps.who.int/iris/bitstream/10665/94384/1/9789241506236_eng.pdf.

3. World Health Organization (WHO). Indicators for assessing infant and young child feeding practices: conclusions of a consensus meeting held 6-8 November 2007 in Washington D.C., USA. Washington, D.C.: World Health Organization (WHO); 2008

4. Rosa W, editor. Transforming our world: the 2030 agenda for sustainable development. In: A new era in global health [Internet]. New York, NY: Springer Publishing Company; 2017. http://connect.springerpub.com/ lookup/doi/10.1891/9780826190123.ap02.

5. Kumar S, Kumar N, Vivekadhish S. Millennium development goals (MDGs) to sustainable development goals (SDGs): addressing unfinished agenda and strengthening sustainable development and partnership. Indian J Community Med Off Publ Indian Assoc Prev Soc Med. 2016:41(1):1.

6. de Onis M, Dewey KG, Borghi E, Onyango AW, Blössner M, Daelmans B, et al. The World Health Organization's global target for reducing childhood stunting by 2025: rationale and proposed actions. Matern Child Nutr. 2013; 9(Suppl 2):6-26.

7. FAO, editor. The multiple dimensions of food security. Rome: FAO; 2013. 52 p. (The state of food insecurity in the world).
8. Martorell R. Improved nutrition in the first 1000 days and adult human capital and health. Am J Hum Biol Off J Hum Biol Counc [Internet]. 2017. https://www.ncbi.nlm.nih.gov/pmc/articles/PMC5761352/.

9. Bailey RL, West KP Jr, Black RE. The epidemiology of global micronutrient deficiencies. Ann Nutr Metab. 2015;66(2):22-33.

10. Pinstrup-Andersen P. Agricultural research and policy for better health and nutrition in developing countries: a food systems approach. Agric Econ. 2007;37(s1):187-98.

11. Guralnik JM, Eisenstaedt RS, Ferrucci L, Klein HG, Woodman RC. Prevalence of anemia in persons 65 years and older in the United States: evidence for a high rate of unexplained anemia. Blood. 2004 15;104(8):2263-8.

12. Rice AL, Sacco L, Hyder A, Black RE. Malnutrition as an underlying cause of childhood deaths associated with infectious diseases in developing countries. Bull World Health Organ. 2000;15.

13. You D, Hug L, Ejdemyr S, Idele P, Hogan D, Mathers C, et al. Global, regional, and national levels and trends in under-5 mortality between 1990 and 2015, with scenario-based projections to 2030: a systematic analysis by the UN Inter-Agency Group for Child Mortality Estimation. The Lancet. 2015; 386(10010):2275-86

14. Hoddinott J, Alderman H, Behrman JR, Haddad L, Horton S. The economic rationale for investing in stunting reduction. Matern Child Nutr. 2013;9(\$2):69-82.

15. Díaz-martínez $\mathrm{E}$, Gibbons $\mathrm{E}$. The questionable power of the Millennium Development Goal to reduce child mortality. J. Hum. Dev. Capab. 2014;15: 2-3 203-217.

16. Bhutta ZA, Das JK, Rizvi A, Gaffey MF, Walker N, Horton S, et al. Evidence-based interventions for improvement of maternal and child nutrition: what can be done and at what cost? Lancet Lond Engl. 2013; 3;382(9890):452-77.

17. Black RE, Victora CG, Walker SP, Bhutta ZA, Christian P, de Onis M, et al. Maternal and child undernutrition and overweight in low-income and middle-income countries. Lancet Lond Engl. 2013;3;382(9890):427-51.

18. Black RE, Allen LH, Bhutta ZA, Caulfield LE, de Onis M, Ezzati M, et al. Maternal and child undernutrition: global and regional exposures and health consequences. Lancet Lond Engl. 2008;19;371(9608):243-60.

19. Danaei G, Andrews KG, Sudfeld CR, Fink G, McCoy DC, Peet E, et al. Risk factors for childhood stunting in 137 developing countries: a comparative risk assessment analysis at global, regional, and country levels. PLoS Med [Internet]. 2016. https://www.ncbi.nlm.nih.gov/pmc/articles/PMC5089547/.

20. Myatt M, Khara T, Schoenbuchner S, Pietzsch S, Dolan C, Lelijveld N, et al. Children who are both wasted and stunted are also underweight and have a high risk of death: a descriptive epidemiology of multiple anthropometric deficits using data from 51 countries. Arch Public Health [Internet]. 2018. https:// archpublichealth.biomedcentral.com/articles/10.1186/s13690-018-0277-1.

21. Brug J. Determinants of healthy eating: motivation, abilities and environmental opportunities. Fam Pract. 2008;1;25(Supplement 1):150-5.

22. Corsi DJ, Neuman M, Finlay JE, Subramanian S. Demographic and health surveys: a profile. Int J Epidemiol. 2012;1;41(6):1602-13.

23. WHO Multicentre Growth Reference Study Group, Onis M. WHO Child Growth Standards based on length/height, weight and age: WHO Child Growth Standards. Acta Paediatr. 2007;2;95:76-85.

24. Rutstein SO, Staveteig S. Making the Demographic and Health Surveys Wealth Index comparable; 2014.

25. Szklarska A, Jankowska EA. Independent effects of social position and parity on body mass index among Polish adult women. J Biosoc Sci. 200;35(4):575-83.

26. Walters S, Suhrcke M. Socioeconomic inequalities in health and health care access in central and eastern Europe and the CIS: a review of the recent literature. Copenhagen, WHO Regional Office for Europe (Working paper 2005/1).

27. Bado AR, Sathiya Susuman A. Women's education and health inequalities in under-five mortality in selected sub-Saharan African countries, 1990-2015. Carpenter DO, editor. PLOS ONE. 2016;21;11(7):e0159186.

28. Jann B. Estimating Lorenz and concentration curves in Stata. SJ. 2016; 16(4):837-66.

29. Van de Poel E. Socioeconomic inequality in malnutrition in developing countries. Bull World Health Organ. 2008;1;86(4):282-91.

30. Wagstaff A, Watanabe N. Socioeconomic inequalities in child malnutrition in the developing world [Internet]. The World Bank; 1999. (Policy Research Working Papers). http://elibrary.worldbank.org/doi/book/10.1596/1813-945 $0-2434$. 


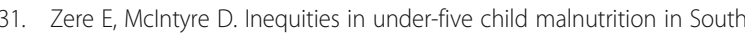
Africa. Int J Equity Health. 2003;11;2:7.

32. Emamian MH, Fateh M, Gorgani N, Fotouhi A. Mother's education is the most important factor in socio-economic inequality of child stunting in Iran. Public Health Nutr. 2014;17(9):2010-5.

33. Kanjilal B, Mazumdar P, Mukherjee M, Rahman MH. Nutritional status of children in India: household socio-economic condition as the contextual determinant. Int J Equity Health. 2010;9(1):19.

34. Uthman OA. Using extended concentration and achievement indices to study socioeconomic inequality in chronic childhood malnutrition: the case of Nigeria. Int J Equity Health. 2009;8(1):22

35. Holakouie Naieni K, Fotouhi A, Borhani M, Pooya B. Risk Factors for malnutrition in 6- to 30-months old children seen at health centers in Hormozgan Province. Iran J Epidemiol. 2006;15;1 (3):27-32.

36. Sharifzadeh $\mathrm{G}$, Mehrjoofard $\mathrm{H}$, Raghebi S. Prevalence of malnutrition in under 6-year olds in South Khorasan. Iran. Iran J Pediatr. 2010;20(4):435-41.

\section{Publisher's Note}

Springer Nature remains neutral with regard to jurisdictional claims in published maps and institutional affiliations.

\section{Submit your manuscript to a SpringerOpen ${ }^{\circ}$ journal and benefit from:}

- Convenient online submission

- Rigorous peer review

- Open access: articles freely available online

High visibility within the field

- Retaining the copyright to your article

Submit your next manuscript at $\boldsymbol{\nabla}$ springeropen.com 